\title{
Multidisciplinary pain management programs
}

This article was published in the following Dove Press journal:

Journal of Pain Research

7 May 2013

Number of times this article has been viewed

\section{Ulrike Kaiser' \\ Bernhard Arnold ${ }^{2}$ \\ Michael Pfingsten ${ }^{3}$ \\ Bernd Nagel ${ }^{4}$ \\ Johannes Lutz ${ }^{5}$ \\ Rainer Sabatowski ${ }^{1,6}$ \\ 'Comprehensive Pain Center, University Hospital "Carl Gustav Carus", Dresden, ${ }^{2}$ Department of Pain Management, Klinikum Dachau, Dachau, ${ }^{3}$ Pain Clinic, University Medicine, University of Göttingen, ${ }^{4}$ Day Care Unit, DRK Pain Center, Mainz, ${ }^{5}$ Interdisciplinary Pain Center, Zentralklinik Bad Berka, Bad Berka, ${ }^{6}$ Department of Anesthesiology and Intensive Care, University Hospital "Carl Gustav Carus", Dresden, Germany}

Correspondence: Rainer Sabatowski Comprehensive Pain Center, University Hospital "Carl Gustav Carus", Technical University Dresden, Fetscherstr 74, 01307 Dresden, Germany Tel +49 35I 4583354

Email rainer.sabatowski@uniklinikumdresden.de

\section{Dear editor}

Multidisciplinary pain management programs based on the bio-psycho-social model are an important tool in the treatment algorithm of chronic non-cancer pain. ${ }^{1,2}$ The programs have been proven to be effective for the treatment of chronic back pain and are also recommended by the current German guidelines for the treatment of low back pain. ${ }^{3-7}$ Common features of all multidisciplinary treatment programs are the high treatment intensity (mean 27 hours per week, period 15-25 days), standardized group sizes (closed groups) and standardized treatment approaches. ${ }^{8,9}$

Artner et al analyzed the short-term outcome of a 3-week intensive multidisciplinary outpatient program for patients suffering from back pain and sciatica retrospectively. ${ }^{10}$ The intensive treatment consisted of interventional injection techniques (eg, epidural, periradicular and facet joint injections) with a frequency of up to 8 injections per patient and additional multiple treatment approaches such as modification of analgesic medication, ergotherapy, massage therapy, back education, transcutaneous electrical nerve stimulation and aquatraining. Behavioral management, offered by physiotherapists, was performed twice a week. The implementation of psychosomatic therapy depended on the degree of chronification and psychological cofactors and was optional. However it was used with increased frequency over the time period observed. Baseline and outcome parameters were assessed using only the Numeric Rating Scale (NRS) and Oswestry Disability Index (ODI). ${ }^{10}$ They concluded that the short-term results of their treatment program were clinically significant in improving pain as well as in functionality. A catamnestic measurement was not included in the results.

The integration of different components of therapy for chronic pain and the concentration on interdisciplinary interventions as described by Artner et al is positive. However, there are important limitations in this study concerning methodological and conceptional aspects and that for the reasons listed below, the treatment program, as provided, cannot be recognized as a multimodal program according to current national recommendations. ${ }^{8}$

\section{Conceptional limitations}

The therapy program is defined differently throughout the paper (intensive interdisciplinary therapy versus special orthopedic pain management program versus conservative 
treatment), which is problematic as it remains unclear, what Artner et al regards as the fundamental basis of their treatment program. ${ }^{10}$ One major limitation includes the lack of implementation of minimal standards in multimodal pain therapy as defined by a special working group of the German chapter of the International Association for the Study of Pain (IASP). ${ }^{8}$

According to Guzman, interventions of less than 100 hours do not show improvements in clinically relevant outcomes for patients suffering from disabling low back pain in multidisciplinary bio-psycho-social rehabilitations programs. ${ }^{1}$ Concerning the treatment duration, the setting of Artner et al can be defined as being "intensive". Unfortunately the use of the term "interdisciplinarity" is most often not clearly defined and therefore might be misunderstood. According to the German Pain Society, interdisciplinary multimodal pain therapy is defined as the simultaneous, contextual, temporal and coordinated, comprehensive strategy to treat chronic pain patients integrating different somatic, physical, as well as psychological, treatment approaches by an interdisciplinary therapeutic team with consensual therapeutic aims. ${ }^{8}$ The standardized treatment is performed by a team of physicians of different disciplines, psychotherapists or clinical psychologists and other disciplines such as physiotherapists, ergo therapists, and others. Under the supervision of a physician, who is specialized in pain management, each of these disciplines is equal in value. Regular team meetings for the evaluation of the individual treatment progress are mandatory. Functional restoration with increasing controllability and self-efficacy are the central aims approach. ${ }^{8}$ According to these recommendations, the procedure as described by Artner et al might be regarded as sufficient in terms of team meetings and the involvement of physicians and physiotherapists. However, psychotherapists do not seem to be integrated in the team on a regular basis which may result in significant consequences in diagnostic, as well as in therapeutic issues. Furthermore it seems to be evident, that not all participating disciplines are equal. The indication of a major component of the program (injection procedures) is determined by the orthopedic surgeon only without having a team consensus. ${ }^{10}$

Additionally, Artner et al mention several therapeutic methods, but most of them are of primarily passive origin, non-activating treatment options (eg, injections, massage). According to the principles of functional restoration it is recommended to use activating methods and avoid passive ones. Spinal and facet joint injections seemed to be the one essential part of the treatment regimen. ${ }^{10}$ This is surprising, as Staal et al already noticed that there is insufficient scientific evidence on the effects of injection therapy, regardless of type and dosage, for patients with subacute and chronic low-back pain. ${ }^{11}$ Furthermore, Niemier recently reported on long-term effects of interventional treatment in patients suffering from musculoskeletal pain. Patients were repeatedly treated (minimum 5 times) and received multiple single injections (eg, epidural, periradicular and facet joint injections) comparable to those performed by Artner et al. ${ }^{10,12}$ However, contrary to the results of Artner et al, this treatment process led to deterioration with a generalization of pain as well as an increase in pain medication and psychosocial impairment. ${ }^{12}$ In their publication Artner et al did not even discuss these contradictory findings.

Some patients received nerve root injections in cases of nerve root compromise with disc herniation or lateral spinal stenosis. The question arises as to whether these patients experienced symptoms that should have been classified as so-called "red flags" and why they didn't receive a specific treatment in contrast to a non-specific treatment, as performed in this study. ${ }^{7,10}$

In the study of Artner et al a standardized treatment approach cannot be detected at all. The treatment approaches seemed to be highly individualized with surprisingly high numbers of invasive techniques and passive interactions, such as spa therapy, massage and fango therapy. This treatment approach is in conflict to the self-claimed aims of the authors to increase the activity levels of the patients, which can only be achieved in chronic pain patients by using adequate active therapies. Furthermore, most of the passive treatment approaches (eg, spa therapy, fango) are not recommended by current guidelines on the treatment of back pain. ${ }^{7}$ Surprisingly the Agency for Healthcare Research and Quality, which was quoted by Artner et al to confirm their approach, submitted a different recommendation: Passive modes (eg, ultrasound, electrical stimulation, massage) are generally avoided in multidisciplinary pain programs. ${ }^{10,13}$ Due to the lack of standardization and the retrospective design of the study, the treatment results cannot be assigned to a specific procedure. However, the infrequent use of psychosomatic therapy in contrast to the high numbers of invasive treatments seems to suggest the importance of the latter.

The diagnostic procedures, which are important for the complete treatment process, were not sufficiently described by Artner and colleagues. An adequate interdisciplinary assessment is crucial, as it controls patients' flows (eg, who should participate on a multimodal program, who should undergo another treatment). Furthermore, risk factors (eg, red and yellow flags) may have been identified and even have a major 
impact on the outcome itself. ${ }^{14}$ The outcome of the 3-week period was described by means of NRS and ODI score changes only; the emotional state (eg, fear, depression) and subjective quality of life often are of more importance in these types of patients. There is much evidence of comorbidity in chronic pain patients concerning psychological cofactors. ${ }^{15,16}$

The choice of psychotherapeutic procedure was surprising for the diagnostic instrument as well as for the therapeutic approach. A non pain-specific approach was chosen, which focuses more on interventions for the treatment of personality disorders. ${ }^{17}$ An approach which exclusively addresses the change of personality disorders is inappropriate for a treatment period of three weeks only, as well as for patients suffering from chronic pain. There are many therapeutic interventions in cognitive-behavioral therapy, which are contrived for the same time duration of 3 or 4 weeks and are well investigated. ${ }^{21}$

Finally the therapy contents such as physical activations and physical home exercise program, relaxation techniques, pain reducing strategies have to be transferred to normal life. ${ }^{13}$ This has to be taken into account to maintain and prove therapeutic effects. Strategies like these are not described in the study and therefore it seems that they have not been implemented at all.

\section{Methodological aspects}

The characterizing of the population is not satisfying. It lacks a profound profile of patients' characteristics. No detailed information is given on pain duration or on previous pain management (eg, drug treatment) at baseline. Furthermore information is missing on the status of chronicity and severity (eg, Mainz Pain Stage System, von Korff Grading System) as well as physical and psychological comorbidities. ${ }^{19-22}$ Even though there are well described procedures in Germany to describe patients' state of chronicity, this was only defined by the minimum duration of back pain ( $>3$ months). ${ }^{20,21}$ However, pain duration is not a valid measure to define the patients' state of chronicity, because there is only a small overlap between duration of pain and the other aspects of chronicity, such as pain behavior, occupation of health providers, medical use and abuse. Hence, in this study discrimination between acute and chronic pain is therefore not possible.

The inclusion procedure of patients was not sufficiently described; indeed there were 15 patients, who were excluded from the analysis with a lack of information concerning the underlying reasons for exclusion.

The lack of more detailed patients' characteristics makes the identification of influencing variables and therapeutic effects impossible. The implementation of a different therapy-group, the comparison of different subgroups (eg, subgroups of high or low chronicity) or, ideally, the use of a control group could have helped a lot. ${ }^{13,23}$ None of these alternatives was chosen.

Additionally, the time interval of measuring an effect (after 15 days) is unreasonable in investigating chronic pain. Furthermore measuring pain intensity four times a day does not make any sense in the therapy of chronic pain, but seems to set the focus on the immediate outcome after interventional injections. For the defined outcome of improving functional restoration the approach is very complex and demands learning as well as behavioral changes for patients. ${ }^{6,24}$ That is why the focus lies in the maintenance of behavioral changes beyond the actual intervention period. An interval of 1 or 2 , even 3 years is commonly used to describe therapy outcomes of chronic pain patients. , $^{3,4,25}$

Due to the limitations of the design the results are not able to be interpreted (lacking internal validation) and generalized (lacking external validation).

Artner et al concluded that the intensive multidisciplinary program appears to have good short-term clinical results for reduction in functional disability and pain. ${ }^{10}$ However, due to significant methodological problems (eg, lack of standardization; missing characterization of the study population), as well as problems in the process quality (eg, orthopedic surgeon determines indications for spinal injection) and conceptual difficulties, the conclusions cannot be followed. The efficacy of multimodal treatment programs dealing with chronic pain conditions can only be demonstrated when long-term follow-ups are performed. A measurement at the end of a short-term period without having a control group cannot distinguish between a treatment and a non-specific effect (eg, due to the fact of intensive passive care being provided in the treatment period) or even a placebo effect. The study offers inadmissible evidence for their conclusions. There is no reason to assume a therapeutic effect of the presented treatment on chronic pain.

\section{Disclosure}

The authors report no conflicts of interest in this work.

\section{References}

1. Guzman J, Esmail R, Karjalainen K, et al. Multidisciplinary rehabilitation for chronic low back pain: systematic review. BMJ. 2001;322:1511-1516

2. Guzman J, Esmail R, Karjalainen K, et al. Multidisciplinary bio-psychosocial rehabilitation for chronic low back pain. Cochrane Database Syst Rev. 2002;1: CD000963. 
3. Schütze A, Kaiser U, Ettrich U, et al. Evaluation of a multimodal pain therapy at the University Pain Centre Dresden. Schmerz. 2009;23: 609-617.

4. Pöhlmann K, Tonhauser T, Joraschky P, Arnold B. The Dachau multidisciplinary treatment program for chronic pain. Efficacy data of a diagnosis-independent multidisciplinary treatment program for back pain and other types of chronic pain. Schmerz. 2008;23:40-46.

5. Neubauer E, Zahlten-Hinguranage A, Schiltenwolf M, Buchner M. Multimodal therapy patients with chronic cervical and lumbar pain. Results of a comparative prospective study. Schmerz. 2006;20:210-218.

6. Hildebrandt J, Pfingsten M. From GRIP to multimodal pain therapy. A concept asserts itself. Orthopäde. 2009;38:885-895.

7. Bundesärztekammer (BÄK), Kassenärztliche Bundesvereinigung (KBV), Arbeitsgemeinschaft der Wissenschaftlichen Medizinischen Fachgesellschaften (AWMF). Nationale VersorgungsLeitlinie Kreuzschmerz Langfassung. [National guideline low back pain - unabbridged version]. Version February 1, 2011. Available from: http://www.versorgungsleitlinien.de/themen/kreuzschmerz. Accessed October 30, 2012. German.

8. Arnold B, Brinkschmidt T, Casser HR, et al. Multimodal pain therapy: principles and indications. Schmerz. 2009;23:112-120.

9. Nagel B, Pfingsten M, Brinkschmidt T, et al; für die Ad-hoc-Kommission "Multimodale interdisziplinäre Schmerztherapie der Deutschen Schmerzgesellschaft" [Structure and process quality of multimodal pain therapy: Results of a survey of pain therapy clinics]. Schmerz. 2012;26:661-669. German.

10. Artner J, Kurz S, Cakir B, Reichel H, Lattig F. Intensive interdisciplinary outpatient pain management program for chronic back pain: a pilot study. J Pain Res. 2012;5:209-216.

11. Staal JB, de Bie R, de Vet HCW, Hildebrandt J, Nelemans P. Injection therapy for subacute and chronic low-back pain. Cochrane Database of Systematic Reviews, 2008;3:CD001824.

12. Niemier K. Long-term effects of interventional treatment on chronic pain of the musculoskeletal system. Retrospective outcome study of repeated in-patient treatment. Schmerz. 2012;26:185-191.

13. Agency for Healthcare Research and Quality. Effective healthcare program. Technical brief: multidisciplinary pain programs for chronic non-cancer pain. 2011. Available from: http://effectivehealthcare. ahrq.gov/ehc/products/212/760/TechBrief8_PainProgramsCancer_20110930.pdf. Assessed November 12, 2012.
14. Rothman MG, Ortendahl M, Rosenblad A, Johansson AC. Improved quality of life, working ability, and patient satisfaction after a pretreatment multimodal assessment method in patients with mixed chronic muscular pain: a randomized-controlled study. Clin J Pain. 2013;29:195-204.

15. Beesdo K, Jacobi F, Hoyer J, et al. Pain associated with specific anxiety and depressive disorders in a nationally representative population sample. Soc Psychiat Epidemiol. 2010;45: 89-104.

16. Hueppe A, Raspe H. Amplified back pain and comorbidity in the population. Schmerz. 2009;23:275-283.

17. Kernberg O. Severe Personality Disorders: Psychotherapeutic Strategies. New Haven, CT: Yale University Press; 1984.

18. Basler HD. Psychologische Therapie chronischer Kopf- und Rückenschmerzen- ein Schmerzbewältigungsprogramm zur Gruppen- und Einzeltherapie [Psychological therapy of chronic head and back pain - a pain-focused coping program]. München: Quintessenz; 1995. German.

19. Frettlöh J, Maier C, Gockel H, Hüppe M. Validation of the German Mainz Pain Staging System in different pain syndromes. Schmerz. 2003;17(4):240-251.

20. Von Korff M, Ormel J, Keefe FJ, Dworkin SF. Grading the severity of chronic pain. Pain. 1992;50(2):133-149.

21. Gerbershagen HU. Das Mainzer Stadienkonzept des Schmerzes: Eine Standortbestimmung. [The Mainz pain staging system of pain] In: Klingler D, Morawetz R, Thoden U, Zimmermann M, editors. Antidepressiva als Analgetika. Wien: Aarachne; 1996:71-95. German.

22. Pfingsten M, Schöps P, Wille T, Terp L, Hildebrandt J. Classification of chronic pain. Quantification and grading with the Mainz Pain Staging System. Schmerz. 2000;14(1):10-17.

23. Campbell M, Fitzpatrick R, Haines A, et al. Framework for design and evaluation of complex interventions to improve health. $B M J$. 2000;321:694-696.

24. Pfingsten M. Functional restoration - it depends on an adequate mixture of treatment. Schmerz. 2001;15:492-498.

25. Jensen IB, Bergström G, Ljungquist TH, Bodin L. A 3 year follow up of a multidisciplinary rehabilitation programme for back and neck pain. Pain. 115:273-283.
Journal of Pain Research

\section{Publish your work in this journal}

The Journal of Pain Research is an international, peer-reviewed, open access, online journal that welcomes laboratory and clinical findings in the fields of pain research and the prevention and management of pain. Original research, reviews, symposium reports, hypothesis formation and commentaries are all considered for publication.

\section{Dovepress}

The manuscript management system is completely online and includes a very quick and fair peer-review system, which is all easy to use. Visit http://www.dovepress.com/testimonials.php to read real quotes from published authors. 